\title{
Corrigendum: Electrochemical anodisation of Ti-15Zr implant: effect of different voltages and times
}

Sai Bhosle BTech

Graduate Research Assistant, University of Illinois at Chicago, Chicago, IL, USA

\section{Sweetu Patel PhD}

Postdoctoral Fellow, University of Illinois at Chicago, Chicago, IL, USA Mohammad Mahdi Taheril PhD

Postdoctoral Fellow, University of Illinois at Chicago, Chicago, IL, USA

The authors regret that the following author was omitted from the author list in this paper when it was published in Surface Innovations online Ahead of Print on 25 January 2017 (http://dx.doi.org/10.1680/ jsuin.16.00025)
Cortino Sukotjo DDS, PhD

Assistant Professor, University of Illinois at Chicago, Chicago, IL, USA

Tolou Shokuhfar PhD*

Assistant Professor, Department of Bioengineering, University of Illinois at Chicago, Chicago, IL, USA

\section{Christos G. Takoudis PhD}

Professor, Department of Chemical Engineering and Bioengineering, University of Illinois at Chicago, Chicago, IL, USA 